Available online at www.eccomasproceedia.org

Eccomas Proceedia COMPDYN (2021) 2769-2790

ECCOMAS

Proceedia
COMPDYN 2021

$8^{\text {th }}$ ECCOMAS Thematic Conference on Computational Methods in Structural Dynamics and Earthquake Engineering M. Papadrakakis, M. Fragiadakis (eds.)

\title{
STUDYING THE PERFORMANCE OF STONE MASONRY ARCH BRIDGES EMPLOYING IN-SITU MEASUREMENTS AND NUMERICAL PREDICTIONS
}

\author{
G.C. Manos ${ }^{1}$ and N. Simos ${ }^{+}$ \\ ${ }^{1}$ Laboratory of Strength of Materials and Structures, Aristotle University \\ e-mail: gcmanos@civil.auth.gr \\ + Brookhaven National Laboratory, U.S.A.
}

\begin{abstract}
The present study presents a series of in-situ measurements conducted at selected old stone masonry bridges, using up-to-date system identification techniques, in an effort to identify their dynamic characteristics in terms of eigen-frequencies, eigen-modes and damping properties. All these information is part of a data base that can be used in the future as a reference for identifying noticeable changes in these dynamic characteristics as part of a structural health monitoring effort for these bridges. Moreover, this information provides a basis for building realistic numerical simulations towards studying the structural behaviour of such stone masonry bridges and assessing their expected structural behaviour in extreme future seismic events. Selected in-situ measurements are presented together with their use in building numerical models of various levels of complexity. These numerical models are finally utilized in assessing the expected performance of specific case studies of stone masonry bridge structures in Greece towards meeting the demands of extreme events that include design earth-quake loads. The described system identification technique can also be linked to specific actions, such as earthquake activity, and thus serve as warning for specific maintenance counter-measure.
\end{abstract}

Keywords: Stone Masonry Bridges, In-situ Vibration Measurements, System Identification, Numerical Simulation, Foundation Deformability, Plaka Bridge Collapse.

ISSN:2623-3347 @ 2021 The Authors. Published by Eccomas Proceedia. Peer-review under responsibility of the organizing committee of COMPDYN 2021. doi: $10.7712 / 120121.8673 .19021$ 


\section{INTRODUCTION}

In what follows selective results are presented from an extensive study, which focused on old stone masonry bridges that are located mainly in the prefectures of Western Macedonia and Epirus and Thessaly in Greece (Gialeridis 1995, Grassos 2007, Milas 2016, Psimarni et al 2000). These bridges are examples of out-standing stone-masonry construction that was dominant for a long period in these parts of Greece (Figs. 1a and 1b).

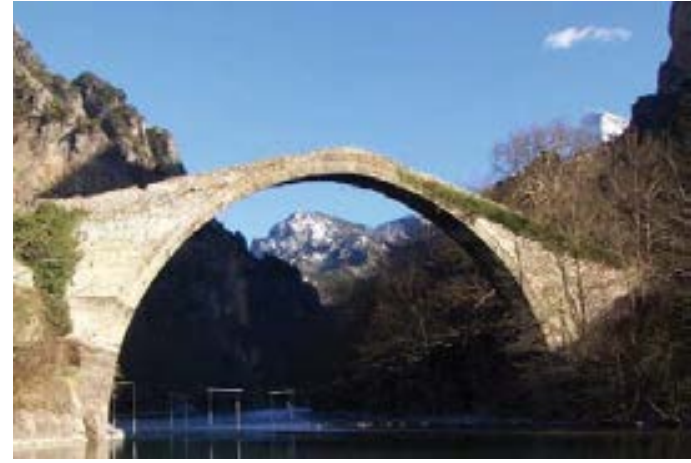

Figure 1a. Konitsa Bridge, Ipiros, Greece.

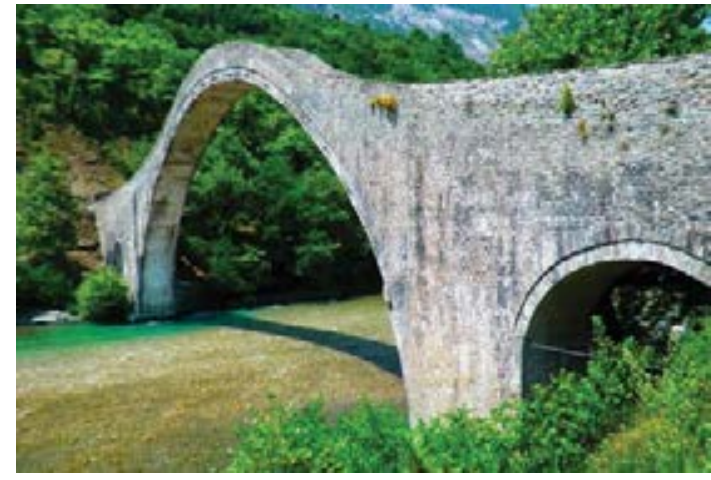

Figure 1b. Plaka Bridge, Ipiros, Greece. (Before its collapse in $1^{\text {st }}$ February 2015)

The use of the stone masonry arch that is utilized in forming stone masonry bridges was extensively used in the times of the Roman Empire as part of the transportation system that was established and linked the various provinces of the Roman Empire. Evidence of stone masonry arch bridges prior to Roman times is not known although stone masonry structures in the East Mediterranean area for other uses date to prehistoric times. A well known use of $\mathrm{arch} / \mathrm{vault}$ stone masonry structural form is the one that can be seen at the royal tombs which have been excavated during the last 200 years in many places in Greece.

The royal tomb of Atraeus at Mycenae-Greece utilized stone masonry to form an underground vaulted structure with a diameter at its base of $14.60 \mathrm{~m}$ and a height of $13.30 \mathrm{~m}$ constructed with 33 subsequent series of stone masonry along the height. The use of such vaulted stone masonry structures demonstrates the efficient utilization of this structural form in order to bear efficiently the dead loads as well as the weight of the overlying soil volume in a state of stress dominated by compression. The use of the stone masonry arch/vault type formation is also evident in the structural system of the royal tombs of the Macedonian kings at Vergina in Northern Greece, dated from 350 B.C. and excavated during the last 30 years. Despite the use of arch/vaulted stone masonry structural formations for these underground Macedonian royal tombs at Vergina in Northern Greece there is no evidence of such structural formations being used for bridges at that time. The remains of an ancient Roman bridge is located between Vergina and Thessaloniki. These remains correspond today to only one main arch with a span of $15 \mathrm{~m}$ and height of $7.5 \mathrm{~m}$. This surviving part of a Roman stone masonry bridge is dated between 50 A.D. and 150 A.D. and it is located at a close distance $(25 \mathrm{~km})$ from the Macedonian palaces of Vergina and Pella and $30 \mathrm{~km}$ from the city of Thessaloniki.

The old stone masonry bridges that survive today have been built during the 18th and 19th century. They were used to connect villages located in rough mountainous terrain bridging currents that could be quite turbulent during part of the year. This type of transporting people, animals and goods was accomplished using a relatively narrow deck with width vary-ing from $2.0 \mathrm{~m}$ to $3.0 \mathrm{~m}$. On the contrary, their size spans from $8 \mathrm{~m}$ to $40 \mathrm{~m}$ when a single arch is employed (Konitsa) or over $70 \mathrm{~m}$ for multi-arch structures (Plaka). More information on the 
geometry, construction characteristics and mechanical properties of the employed materials are given by Manos et al. (2016). Today, these structures have retain but only a small part of this primary function, as new roads and bridges have been built to facilitate the contemporary transportation needs. Despite this fact they have recently attracted considerable attention as cultural heritage structures together with an effort to become parts of a network of mountain trails. Because a number of people use these structures as visitors a conservation effort was also initiated for their maintenance. Our study has also partly such an objective. That is to obtain information through in-situ instrumentation and measurements on the vibration characteristics of these structures at a given time in a health monitoring framework, as described in section 2. In addition, these in-situ measurements are complemented with a numerical investigation that has as first target to form realistic numerical simulations of such old stone masonry structures. Moreover, to employ next such realistic numerical simulations in order to assess the behaviour of these old stone masonry bridges to a combination of loads that include accidental actions, such as forces generated from earthquakes or flooding.

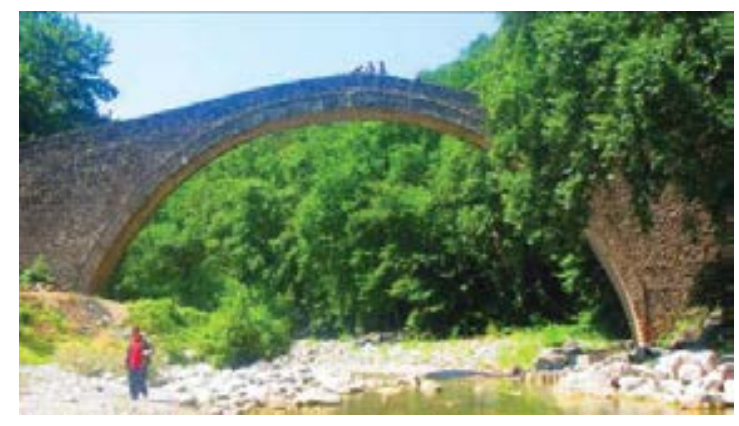

Figure 2a. The studied old stone masonry bridge of Saint Vissariona 23rd August, 2017. Span of main arch $28.9 \mathrm{~m}$ and height $16.3 \mathrm{~m}$

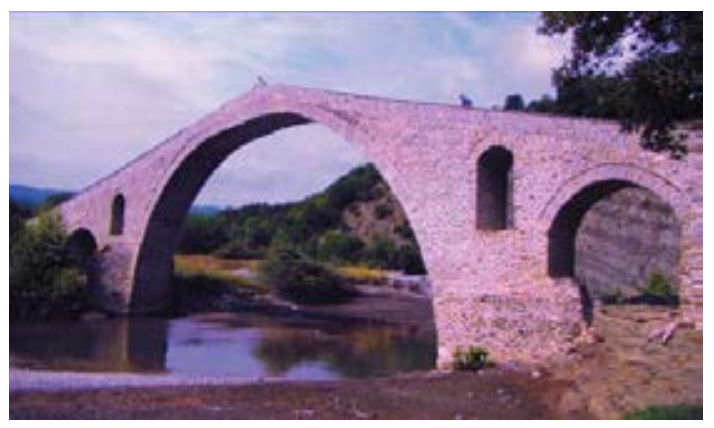

Figure 2b. The studied old stone masonry bridge of Aziz Aga 31st August, 2016. Span of main arch 28m and height $13.5 \mathrm{~m}$.

\section{IN-SITU MEASUREMENTS OF THE DYNAMIC CHARACTERISTICS OF THE STUDIED STONE BRIDGES}

In measuring the dynamic response of all the studied stone bridges two types of excitation were mobilized. The first, namely ambient excitation, mobilized the wind, despite the variation of the wind velocity in amplitude and orientation during the various tests. Due to the topography of the areas where these stone bridges are located, usually a relatively narrow gorge, the orientation of the wind resulted in a considerable component perpendicular to the longitudinal bridge axis. This fact combined with the resistance offered to this wind component by the façade of each bridge produced suffi-cient excitation source resulting in small amplitude vibrations that could be recorded by the employed instrumentation. The second type of excitation that was employed, namely vertical in-plane excitation, was produced from a sudden drop of a weight on the deck of each stone masonry bridge (Aoki 2007, Manos 2015a, 2015b, 2016, 2017, Ozden et al 2012, Ruocci et al. 2013).

The level of this second type of excitation was capable of producing mainly vertical vibrations; however, depending on the location of the stone-bridge that such an excitation was applied, horizontal vibratory response components could also be recorded. From the recorded three-component response the in-plane and out-of-plane eigen-frequencies and eigen-modes of each studied stone masonry bridge structure could be identified. The employed tri-axial velocity sensors had a sensitivity of $0.001 \mathrm{~mm} / \mathrm{sec}$ and a data acquisition system with a sam- 
pling frequency of $800 \mathrm{~Hz}$. The wind orientation relative to the geometry of each bridge structure coupled with the bridge stiffness properties could excite mainly the 1st symmetric out-ofplane eigen-modes. The variability of the wind orientation could also excite, although to a lesser extend, some of the other in-plane and out-of-plane eigen-modes. The drop weight excitation in various locations combined with the placement of the sensors in selected locations was capable of capturing the in-plane as well as out-of-plane modes of response. A careful study of the numerous in-situ response measurements together with the assistance of numerical simulation tools and a back analysis process resulted for such stone bridges in their dynamic system identification. This process is presented in what follows for two old masonry bridges, namely the Saint Vissariona Bridge at Pile, in Trikala prefecture (figure 2a) and the bridge of Aziz-Aga, at Grevena prefecture (figure 2b).

Due to space limitations only selective measurements of the out-of-plane response, which was recorded utilizing either the wind or the drop weight excitation are included here. More information is reported by Manos et al. (2016).
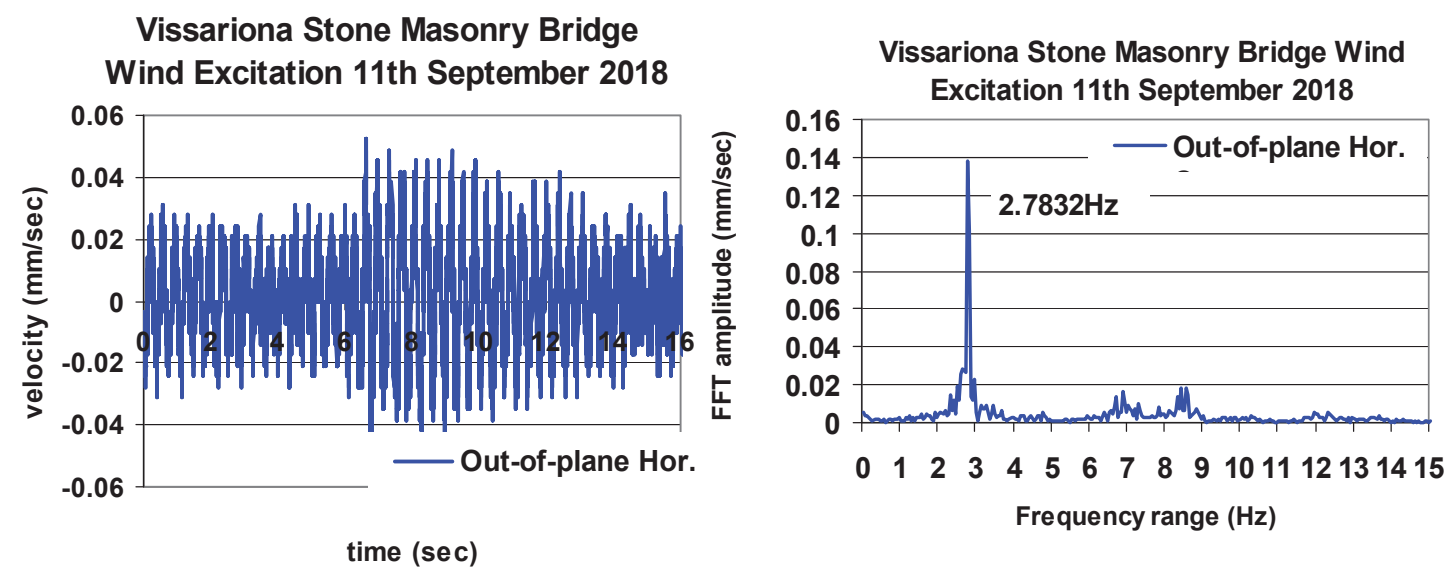

Figure 3. Wind excitation Saint Vissariona Bridge 9th September, 2018. Out-of-plane horizontal component.

Vissariona Stone Masonry Bridge Drop Weight 11th September 2018

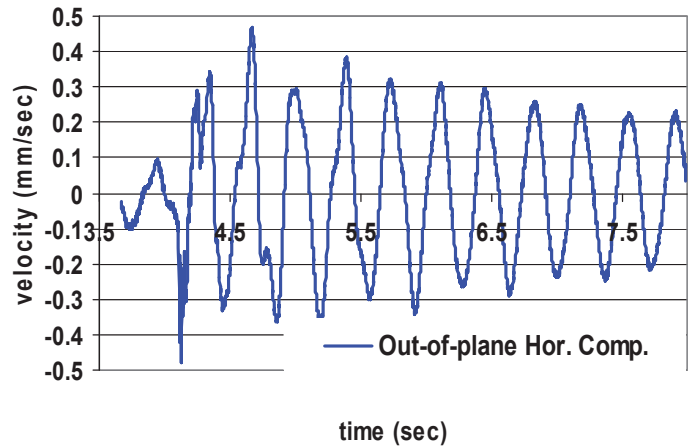

Vissariona Stone Masonry Bridge

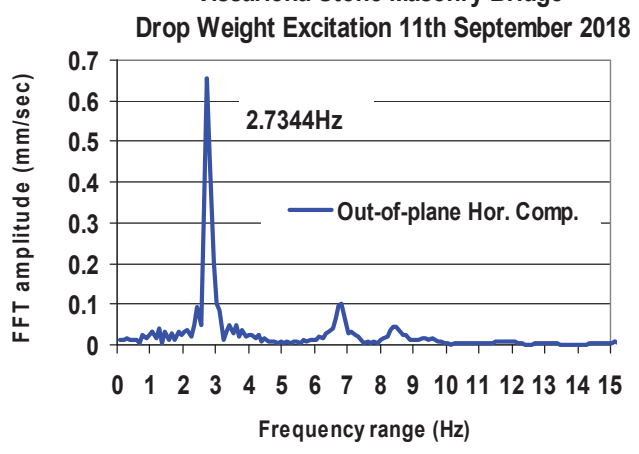

Figure 4. Drop weight excitation Saint Vissariona Bridge 9th September, 2018. Out-of-plane horizontal component.

In figure 3, the out-of-plane horizontal component response of the Saint Vissariona bridge is presented due to wind excitation. The time history plot is shown at the left hand side of this figure with the corresponding FFT plot shown at the right hand side. As dominant frequency 
the value of $2.7832 \mathrm{~Hz}$ can be identified. Figure 4 depicts the corresponding out-of-plane horizontal component response, in terms of time history and FFT plots, for the same bridge due this time to the drop weight excitation. The dominant frequency value is this time equal to $2.7344 \mathrm{~Hz}$. For the Aziz Aga stone bridge the out-of-plane horizontal component response, in terms of time history and FFT plots, due to the drop weight excitation is depicted in figure 5. As can be seen in this figure the dominant eigen-frequency is equal to $3.4668 \mathrm{~Hz}$. By studying further the FFT plots of figures 4 and 5 one can also identify through the other two distinct peaks the eigen-frequencies of two more high-order out-of-plane response eigen-modes.
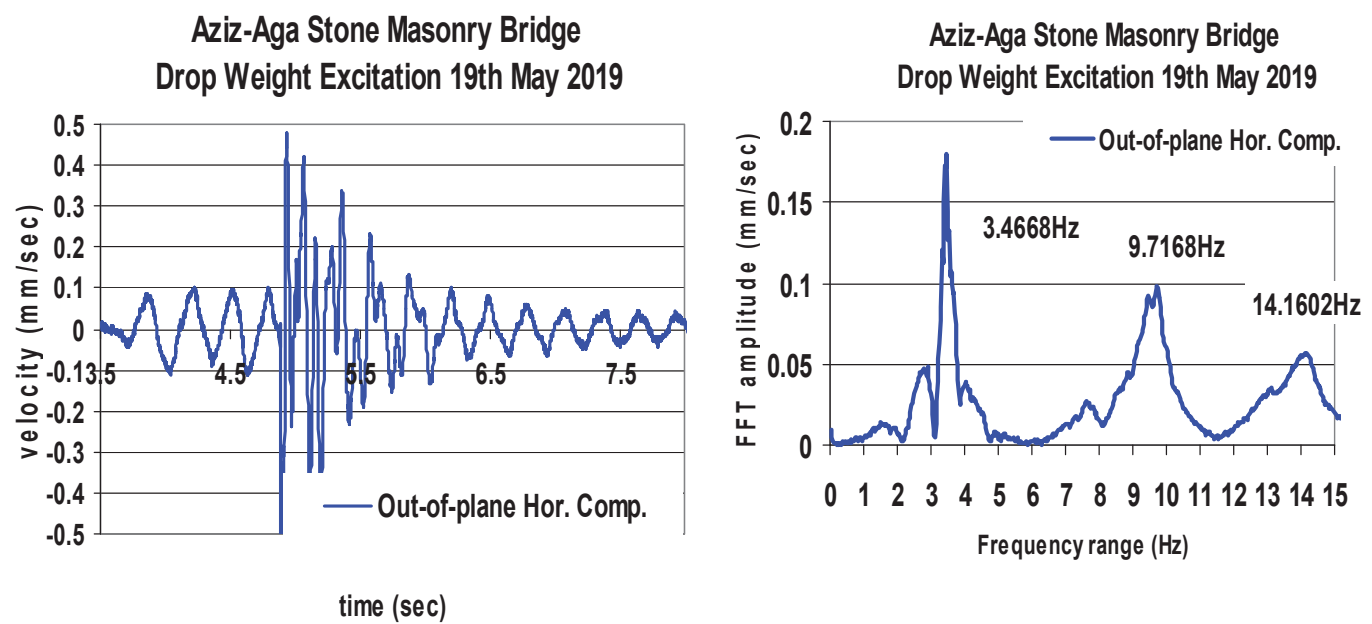

Figure 5. Drop weight excitation Aziz-Aga Bridge 19th May, 2019. Out-of-plane horizontal component

\section{NUMERICAL SIMULATION OF THE DYNAMIC RESPONSE RECORDED IN- SITU UTILIZING LINEAR-ELASTIC RESPONSE ASSUMPTIONS.}

Initially, in the following section an attempt is made to employ a variety of linear-elastic numerical simulations for a relatively simple arch bridge.
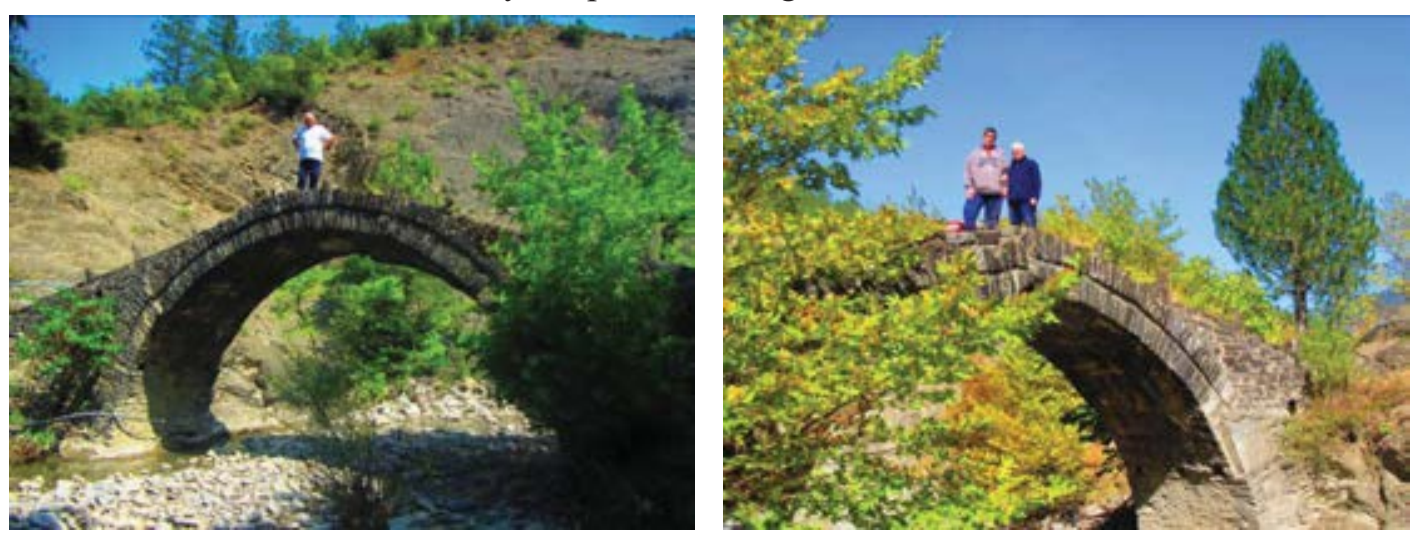

Figure 6. The single arch stone masonry bridge at Kryineri (Molista).

This structure bridges one of the streams that flows towards Sarantaporos river between the mountains of Grammos and Smolikas at the prefecture of Ipirous. This valley was and still is 
one of the main links between the prefectures of Macedonia and Ipirous in Greece. Apart from this bridge there were other bridges in this valley that do not exist today. One of these bridges that survive today, which bridges the upper part of Sarantaporos river near its origin (Eptachori) is the two-arch bridge of Drosopigi, located near the village with the same name, the birth place of the second author of this work (figure 7). Both Drosopigi bridge and the Kryoneri bridge were initially studied numerically by Simos and Manos [24]. In section 3.1. the numerical simulation of the Kryoneri Bridge is again presented together with corresponding measurements performed in-situ.

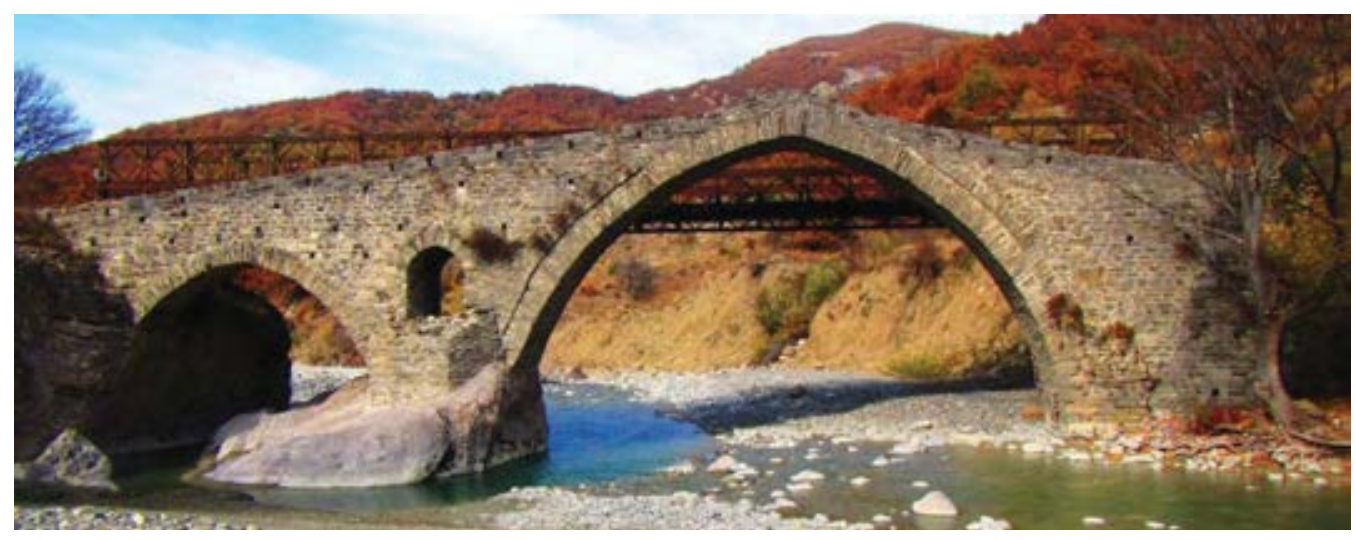

Figure 7. The two-arch stone masonry bridge at Drosopigi.

\subsection{The stone masonry bridge at Kryoneri}

This is a relatively simple stone masonry bridge of a single arch, as shown in figure 6 . The clear span of this bridge is $8.25 \mathrm{~m}$, the height from the river bed to the key of the arch (bottom fiber) $5 \mathrm{~m}$ and the width of this bridge at the key of the arch $2.4 \mathrm{~m}$. Figures $8 \mathrm{a}$ and $8 \mathrm{~b}$ depict the main out-of-plane and in-plane eigen-modes of this bridge, respectively.

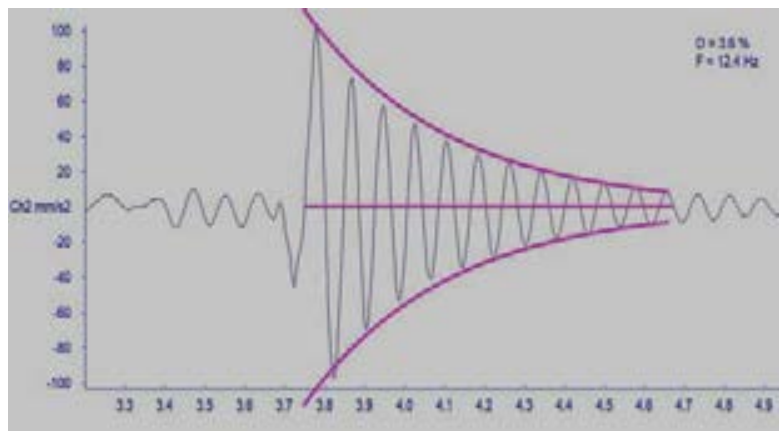

Figure 8a. Out-of-plane 12.744Hz Damping 3.7\%

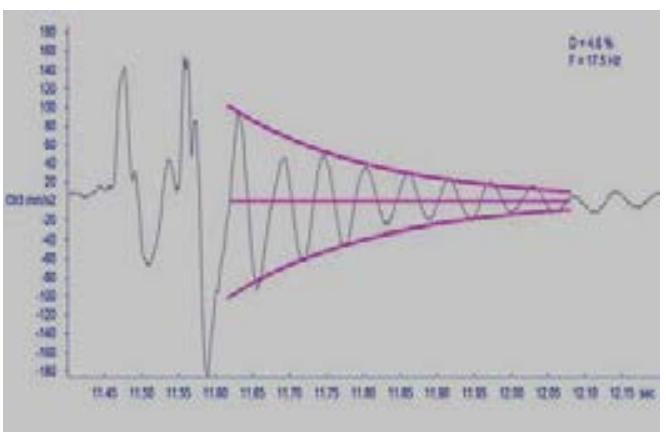

Figure 8b. 1st In-plane $17.578 \mathrm{~Hz}$ Damping $4.6 \%$

As can be seen in figures $8 \mathrm{a}$ and $8 \mathrm{~b}$ the first out-of-plane eigen frequency was measured insitu to be equal to $12.744 \mathrm{~Hz}$, whereas the first in-plane eigen-frequency was measured to be equal to 17.578 , which is considerably higher than the $1^{\text {st }}$ out-of-plane. It must be underlined here that the drop weight excitation process was utilized in situ to obtain these eigenfrequency values. Moreover, from stone samples taken in-situ the following mechanical characteristics were obtained from laboratory tests. 
Table 1. Molista stone cubes. Compression test results November 2018

\begin{tabular}{|l|l|l|l|l|l|l|l|}
\hline $\begin{array}{l}\text { Code } \\
\text { No }\end{array}$ & $\begin{array}{l}\text { Width } \\
(\mathrm{mm})\end{array}$ & $\begin{array}{l}\text { Thickness } \\
\mathrm{nm})\end{array}$ & $\begin{array}{l}\text { Area } \\
\left(\mathrm{mm}^{2}\right)\end{array}$ & $\begin{array}{l}\text { Height } \\
(\mathrm{mm})\end{array}$ & $\begin{array}{l}\text { Slenderness } \\
\text { ratio H/l }\end{array}$ & $\begin{array}{l}\text { Ultimate } \\
\text { Compression } \\
(\mathrm{KN})\end{array}$ & $\begin{array}{l}\text { Ultimate } \\
\text { Compressive } \\
\text { stress }(\mathrm{MPa})\end{array}$ \\
\hline 1 & 61 & 57 & 3477 & 61 & 1.000 & 363.0 & 104.4 \\
\hline 2 & 57 & 60.5 & 3448.5 & 48 & 0.817 & 392.4 & 113.8 \\
\hline 3 & 59 & 57 & 3363 & 70 & 1.207 & 412.0 & 122.5 \\
\hline 4 & 50 & 60.5 & 3025 & 64 & 1.164 & 255.1 & 84.3 \\
\hline
\end{tabular}

The subsequent numerical analysis followed three different numerical simulations. Al of them assumed linear-elastic behaviour and homogenization of the stone masonry. The first approach is the simplest of the three simulating the bridge through the middle longitudinal plane of symmetry utilizing thick shell finite elements, as shown in figure 9. The supports for all the nodes forming the horizontal abutment base contact was assigning zero translations $(\mathrm{ux}=\mathrm{uy}=\mathrm{uz}=0)$ and zero rotations $(\varphi \mathrm{x}, \varphi \mathrm{y}, \varphi \mathrm{z})$ along all three axes. The supports for all the nodes forming the inclined abutment base contact was assigning only zero translations along all three axes $(\mathrm{ux}=\mathrm{uy}=\mathrm{uz}=0)$. The second approach uses brick finite elements and in this way the full geometry of the bridge is portrayed, as shown in figure 10a. In the third approach the numerical simulation includes also the valley substrate as a continuation of the abutments of this bridge in a way shown in figure 10b. In all these analyses the homogenized masonry Young's modulus was assumed equal to $2000 \mathrm{MPa}$ and the homogenized masonry special density $25.5 \mathrm{KN} / \mathrm{m}^{3}$

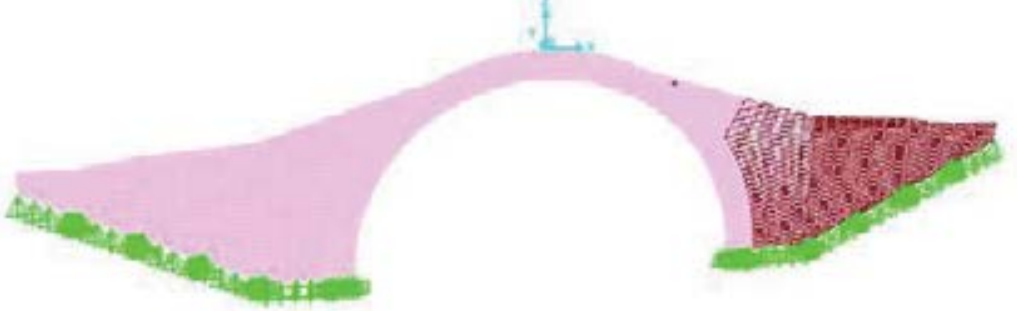

Figure 9. 3-D numerical simulation of the single-arch stone masonry bridge at Kryoneri (Molista) employing thick shell finite elements.
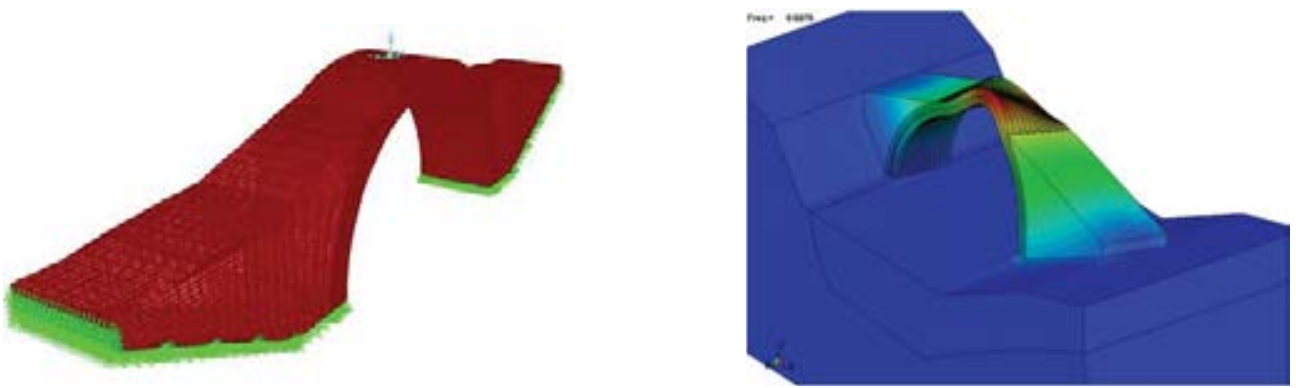

Figure 10. a) 3-D numerical simulation of the single-arch stone masonry bridge at Kryoneri (Molista) employing brick finite elements. b) 3-D numerical simulation of the single-arch stone masonry bridge at Kryoneri (Molista) together with part of the valley substrate employing brick finite elements.

From the eigen-frequency values listed in figure 11 good agreement is reached between the eigen-frequency values obtained by the 3-D numerical simulation of the single-arch stone masonry bridge at Kryoneri (Molista) employing either thick shell finite elements or the 3-D numerical simulation employing brick finite elements. 


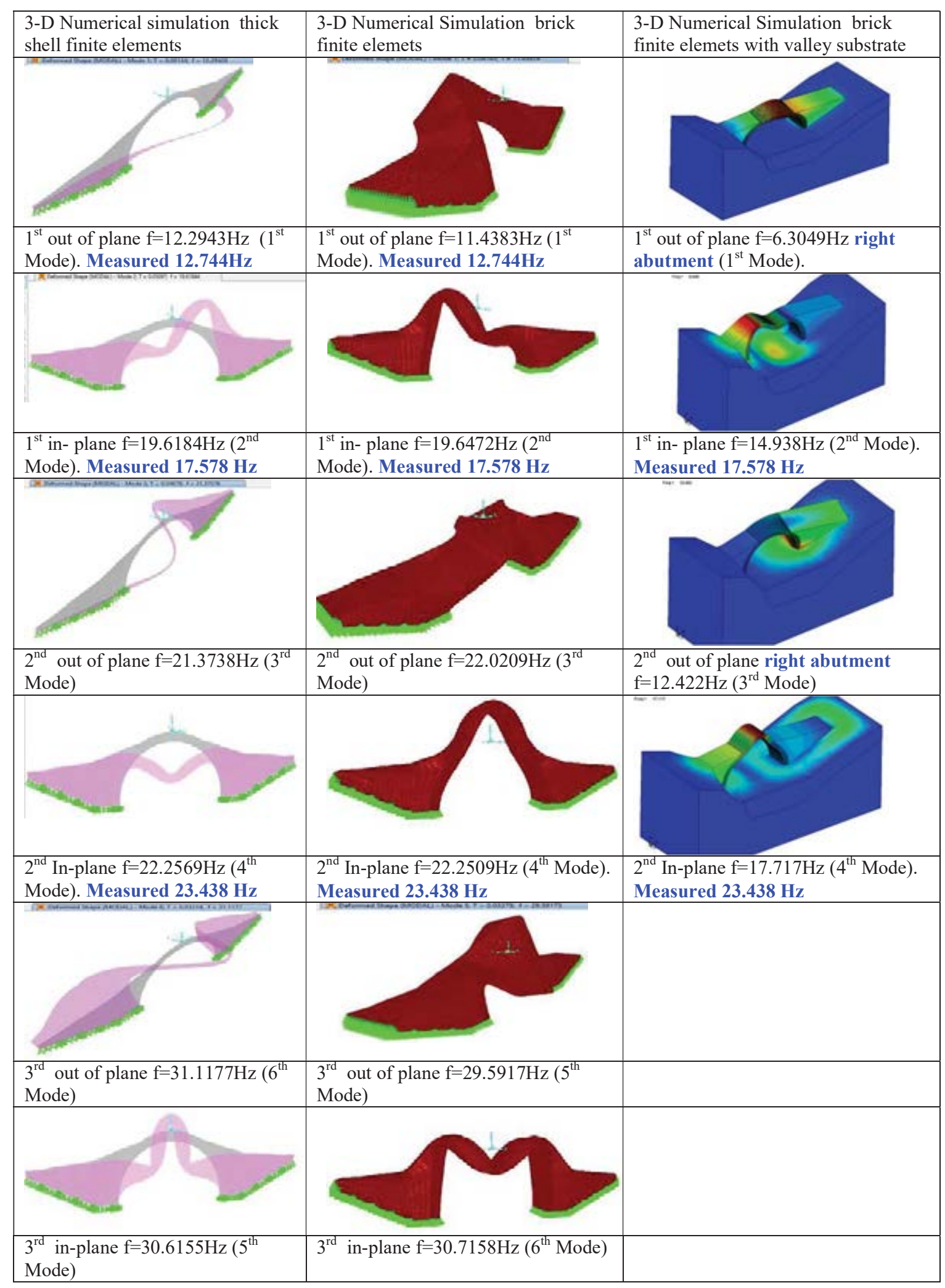

Figure 11. Comparison of numerically obtained eigen-frequencies from the three numerical approaches between themselves and with specific in-situ measured values. 
When comparing the numerical results of the 3-D numerical simulation of the singlearch stone masonry bridge at Kryoneri (Molista) together with part of the valley substrate employing brick finite elements it can be observed that the inclusion of the soft alluvium substrate introduces a considerable flexibility in the structural system as a whole. Moreover, a number of the first in-plane and out-of-plane significant eigen-modes are influenced by the flexibility of the abutments as they are supported on the alluvium substrate. This is underline in both figures 11 and 12. It must be underlined that the used method of excitation is of such an intensity that is unable to mobilize such an interaction between the abutments of the Kryoneri bridge and the alluvium substrate that can be of significance. This is the reason that these numerical values are not compared in figure 11 with the corresponding measured in-situ values.

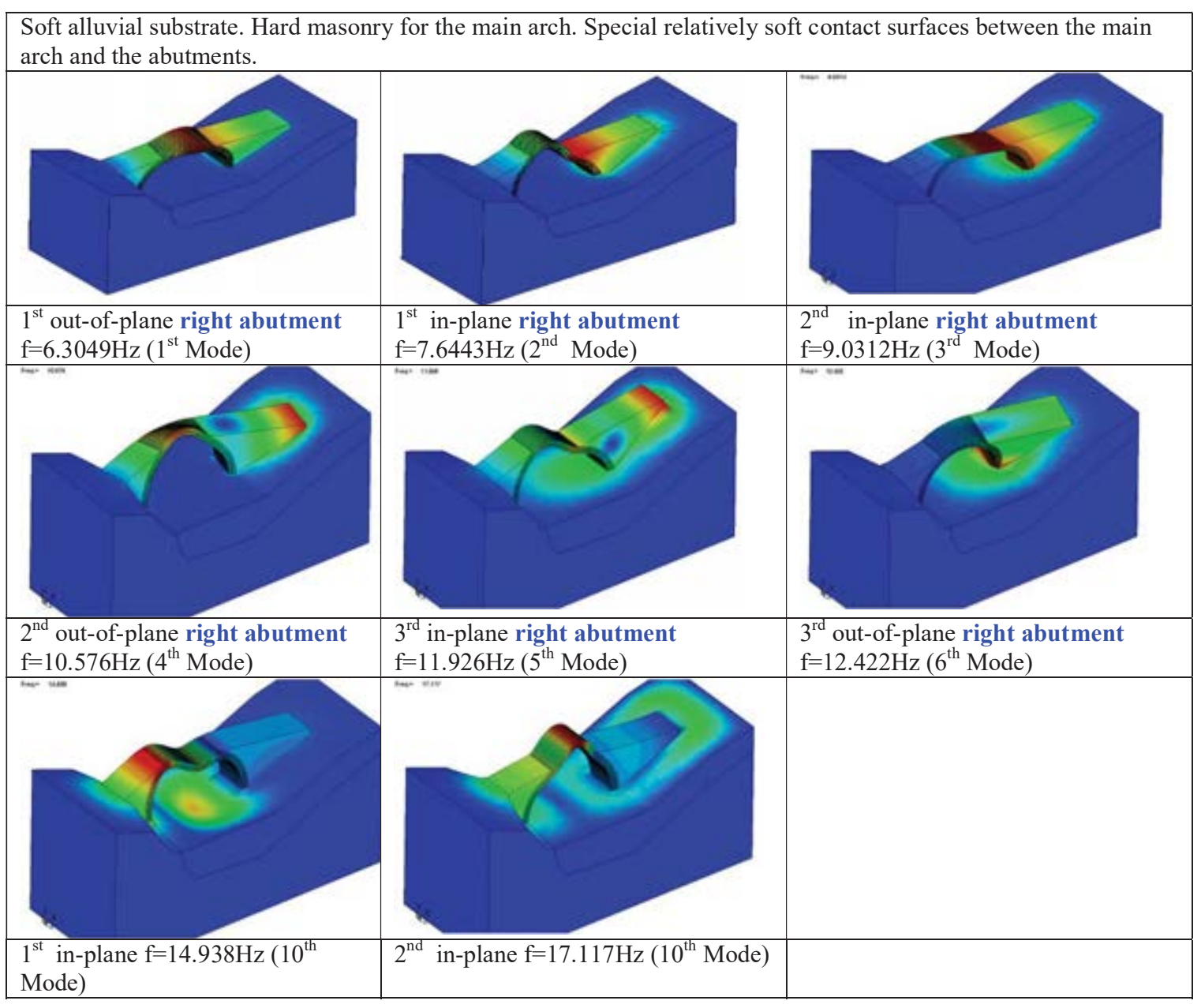

Figure 12. Eigen-modes and eigen-frequencies obtained from a 3-D numerical simulation of the single-arch stone masonry bridge at Kryoneri (Molista) together with part of the valley substrate employing brick finite elements.

\subsection{The numerical simulation of relatively large stone masonry arch bridges}

In this section numerically simulate the eigen-frequencies and eigen-modes of Saint Vissariona and Aziz Aga stone masonry bridges, as they resulted from the dynamic system identification process, based on the measured in-situ numerous dynamic response records. These 
stone masonry arch bridges are much larger than the simple arch bridge examined in section 3.1. At this initial stage the basic assumption of the numerical simulation is the linear elastic response approximation. The overall geometry of the various parts as well as their overall thickness was reproduced as was measured in-situ. The numerical simulation tried to reproduce the primary arch and the secondary arch separately. Moreover, separately were reproduced the abutments and the foundation footings. Thin layers of more flexible material (mortar layers) were introduced in regions where such main parts were connected. Reported by Manos et al. (2016) is a limited study of the mechanical characteristics of stone and mortar samples taken from a prototype bridge which collapsed in 2015 and is currently rebuilt. More information of this bridge's performance is presented by Manos et al. (2019).

Initially, for simplicity purposes, these numerical simulations are made in the 3-D domain representing the bridge structure with its mid-surface employing thick shell finite elements (SAP2000).

Table 2. Measured and predicted eigen-frequencies for Saint Vissariona stone masonry bridge

Eigen-modes and measured eigen-frequencies

\section{(1)}

$1^{\text {st }}$ Out-of-plane

Measured eigenfrequency $2.832 \mathrm{~Hz}$

$2^{\text {nd }}$ Out-of-plane Measured eigenfrequency $5.029 \mathrm{~Hz}$

$1^{\text {st }}$ In-plane

Measured eigenfrequency $7.129 \mathrm{~Hz}$

\section{$3^{\text {rd }}$ Out-of-plane}

Measured eigenfrequency $8.839 \mathrm{~Hz}$

$2^{\text {nd }}$ In-plane Measured eigenfrequency $9.570 \mathrm{~Hz}$

$$
\begin{gathered}
\mathbf{3}^{\text {rd }} \text { In-plane } \\
\text { Measured eigen- } \\
\text { frequency } 13.037 \mathrm{~Hz}
\end{gathered}
$$

3-D numerical simulation with shell elements representing the longitudinal mid-section

\section{(2)}

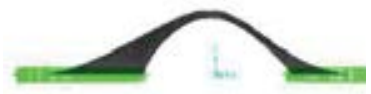

Pred. eigen-frequency $2.784 \mathrm{~Hz}$, $\mathrm{m}_{\mathrm{y}}=40.3 \%$

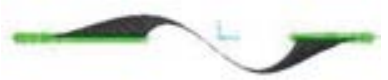

Pred. eigen-frequency $5.270 \mathrm{~Hz}$,

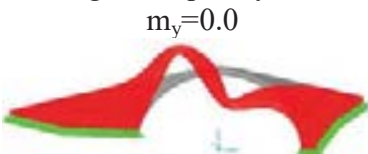

Pred. eigen-frequency $8.38 \mathrm{~Hz}$, $\mathrm{m}_{\mathrm{x}}=9.27 \% \quad \mathrm{~m}_{\mathrm{z}}=0.4 \%$

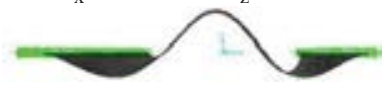

Pred. eigen-frequency $9.184 \mathrm{~Hz}$, $\mathrm{m}_{\mathrm{y}}=20.5 \%$

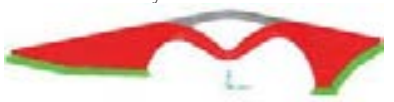

Pred. eigen-frequency $9.45 \mathrm{~Hz}$, $\mathrm{m}_{\mathrm{x}}=0.002 \% \quad \mathrm{~m}_{\mathrm{z}}=9.7 \%$

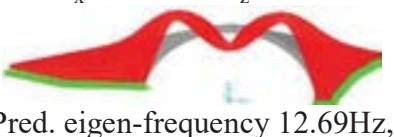

Pred. eigen-frequency $12.69 \mathrm{~Hz}$, $\mathrm{m}_{\mathrm{x}}=0.01 \% \quad \mathrm{~m}_{\mathrm{z}}=14.1 \%$
3-D numerical simulation with solid elements representing the full geometry of the stone bridge

(2)

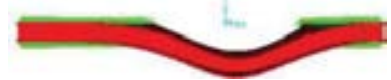

Computed eigen-frequency $2.719 \mathrm{~Hz}$

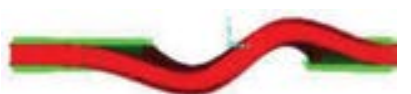

Computed eigen-frequency $5.240 \mathrm{~Hz}$

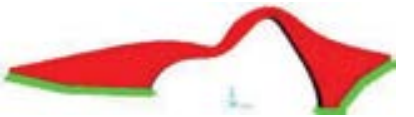

Computed eigen-frequency $8.392 \mathrm{~Hz}$

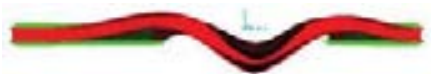

Computed eigen-frequency $8.202 \mathrm{~Hz}$

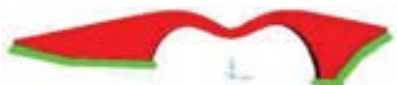

Computed eigen-frequency $9.475 \mathrm{~Hz}$

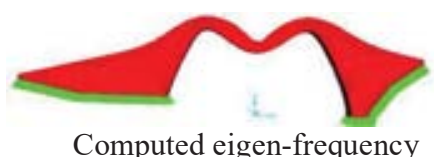

$12.712 \mathrm{~Hz}$

The predicted eigen-frequency values obtained from this type of numerical simulation are listed in column 2 of tables 2 and 3 for the stone masonry bridges of Saint Vissariona and Aziz Aga, respectively. The corresponding modal mass participation ratio values are also listed in this table. The out-of-plane and the in-plane horizontal directions are denoted with the axes $y-y$ and $x-x$, respectively, whereby $z-z$ is the vertical axis. At a second stage an alternative 3-D numerical was carried out whereby all the various parts of each bridge were represented employing solid prismatic finite elements. The predicted eigen-frequency values 
obtained from this type of numerical simulation are listed in column 3 of tables 2 and 3 for the stone masonry bridges of Saint Vissariona and Aziz Aga, respectively.

The corresponding eigen-mode shapes are also included in these tables. The various main parts of this stone masonry bridge, that is the primary and the secondary arches, the abutments, the deck, the mandrel walls and the parapets were simulated in such a way that narrow contact surfaces could be introduced between them, representing in this way a different "softer" medium. All available information, measured during the in-situ campaign, on the geometry of each one of these parts was used in building up these numerical simulations. The mechanical property values obtained from the stone and mortar sample tests were utilized (see Manos et al. (2016). Moreover, there is important information that is needed in order to form with some real-ism the boundary conditions at the river bed and banks. The lack of specific studies towards clarifying in a systematic way all these uncertainties represents a serious limitation in the numerical simulation process. The approximation adopted in this study is a process of back simulation (Manos et al. 2015a, 2015b, Simos et al. 2017, 2018). This is done by adopting values for these unknown mechanical stone masonry properties, respecting at the same time all the measured geometric details, which result in reasonably good agreement between the measured and predicted in this way eigen-frequency values.

Table 3. Measured and predicted eigen-frequencies for Aziz Aga stone masonry bridge

Eigen-modes and measured 3-D numerical simulation with eigen-frequencies

(1)

$1^{\text {st }}$ Out-of-plane

Measured eigen-frequency $3.4670 \mathrm{~Hz}$

$2^{\text {nd }}$ Out-of-plane

Measured eigen-frequency $6.250 \mathrm{~Hz}$

$1^{\text {st }}$ In-plane

Measured eigen-frequency $8.398 \mathrm{~Hz}$

$3^{\text {rd }}$ Out-of-plane

Measured eigen-frequency $7.764 \mathrm{~Hz}$

$2^{\text {nd }}$ In-plane

Measured eigen-frequency $9.375 \mathrm{~Hz}$
$3-D$ numerical simulation with
shell elements representing the longitudinal mid-section

(2)

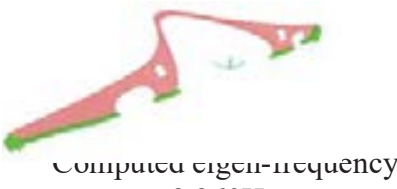
$3.360 \mathrm{~Hz}$

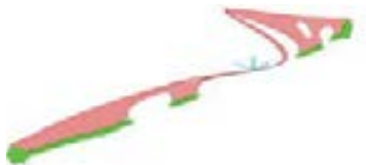

Computed eigen-frequency $5.857 \mathrm{~Hz}$

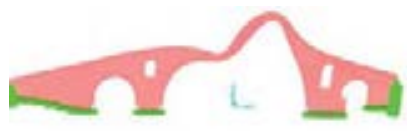

Computed eigen-frequency $7.920 \mathrm{~Hz}$

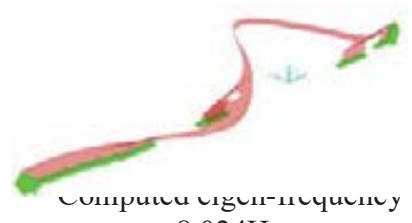

$8.024 \mathrm{~Hz}$

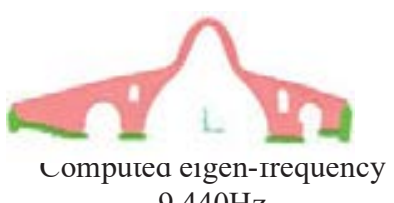

$9.440 \mathrm{~Hz}$
3-D numerical simulation with solid elements representing the full geometry of the stone bridge

(3)
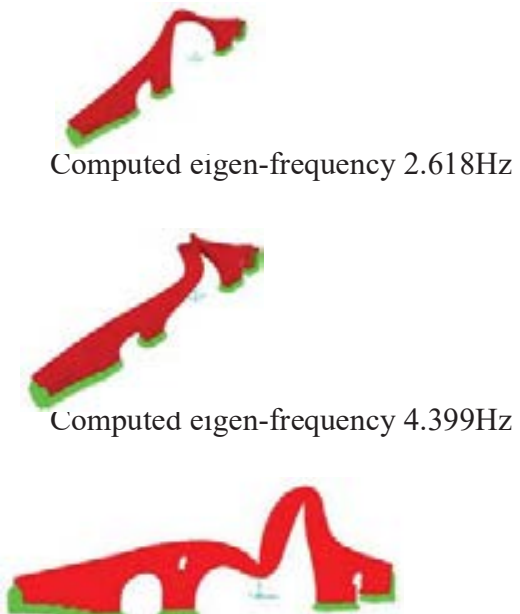

Computed eigen-trequency $7.776 \mathrm{~Hz}$

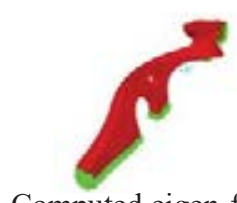

Computed eigen-frequency $6.150 \mathrm{~Hz}$

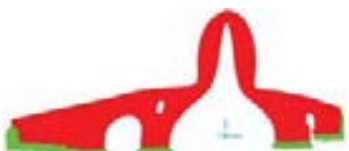

Computed eigen-frequency $9.332 \mathrm{~Hz}$ 
Following this approximate process the boundary conditions introduced in both numerical simulations at all the boundaries, either at the river bed or the river banks, were constraining to zero the translational displacement in the two horizontal and the vertical direction. It was observed from a sensitivity analysis that was performed by Manos et al. (2016) for a number of stone masonry bridges that introducing fixity boundary conditions for the first type of numerical simulation influences, as expected, the out-of-plane and not the in-plane stiffness of the studied stone masonry bridges. Moreover, for the Saint Vissariona and Aziz Aga Bridge whereby the main central arch is supported at the North end in adjacent arches rather than in a rocky river bank the influence of the variation of the boundary conditions, as expected, is again less pronounced.

The value of the corresponding measured eigen-frequency values is included in the first column of tables 2 and 3 . These values, as already mentioned, were obtained from the system identification study for each bridge based on the numerous measurements of the vibratory response recorded in-situ utilizing either wind or drop weight excitations (see figures 3, 4 and 5). When the predicted eigen-frequencies obtained from the shell elements numerical simulation of Saint Vissariona bridge (Table 2 column 2) are compared with those obtained from the solid elements numerical simulation (Table 2 column 3 ) a good agreement is observed for all the listed numerically predicted eigen-modes apart for the third out-of-plane eigen-mode. When this comparison is made between the numerically predicted eigen-frequency values with the ones deduced from the in-situ measurements (Table 2 column 1), a good agreement can be observed for the 1st and 2nd out-of-plane and for the 2nd and 3rd in-plane eigen-modes, for both types of numerical simulations. For the 3rd out-of-plane eigen-mode the numerical simulation employing shell element is in better agreement with the measured value than the numerical simulation employing solid elements. Both types of numerical simulation predict an eigen-frequency value for the 1st in-plane eigen-mode that differs substantially for the measured value. This discrepancy is of need of further research. When the predicted eigenfrequencies obtained from the shell elements numerical simulation of Aziz Aga bridge (Table 3 column 2) are compared with those obtained from the solid elements numerical simulation (Table 3 column 3) a good agreement is observed for all three in-plane numerically predicted eigen-modes but not for the corresponding three out-of-plane eigen-modes. When this comparison is made between the numerically predicted eigen-frequency values with the ones deduced from the in-situ measurements (Table 3 column 1), a good agreement can be observed between the measured and predicted values for the 1st type of numerical simulation employing shell finite elements. The predicted values employing solid finite elements are in reasonable agreement with the measured values only for the in-plane eigen-modes but not for the outof-plane eigen-modes. This must be attributed to the effect of the boundary conditions for the numerical simulation employing solid elements.

\section{SEISMIC BEHAVIOUR OF THE SAINT VISSARIONA BRIDGE}

This section includes results from a series of simplified numerical simulations of the Saint Vissariona stone masonry bridge when it is subjected to a combination of actions that include the dead weight (D) combined with extreme actions generated from seismic ground motions (Sevim Barıs, et al., 2011, Kiyono J., et al. 2012). The seismic forces were defined by making use of the current definition of the seismic forces by EURO-Code 8 (2004). Towards this horizontal design spectral curves were derived (figure 13) based on the horizontal design ground acceleration. This value, as it is defined by the zoning map of the current Seismic Code of Greece, is equal to $0.16 \mathrm{~g}$ ( $\mathrm{g}$ the acceleration of gravity) for the location of the Saint Vissariona bridge located at Pyle Trikala Prefecture of Greece (EAK 2000, ITSAK 2019). Further- 
more, it is assumed that the soil conditions belong to category B because of the bridge is founded near the banks of the river bed and not directly at a rocky sub-terrain. The importance factor was assigned to a value equal to 1.2 whereas the foundation coefficients was as-signed a value equal to one (1.0); the damping ratio is considered equal to $5 \%$ and the behaviour factor is equal to 1.5 (unreinforced masonry).

It must be pointed out that the flexibility of the foundation that was taken into account in the numerical simulation of stone masonry bridges in the past was not considered here. Two types of numerical analyses were performed. In the first type of numerical analysis, the dynamic spectral method was employed making use of the contribution of twelve modes, which include the dominant in-plane and out-of-plane eigen-modes. Moreover, an amplification factor was introduce in order to compensate for the fact that only a portion of the total mass is mobilized by these eigen-modes in the in-plane and out-of-plane directions. In the second type of numerical analysis equivalent horizontal seismic forces are applied either in the inplane (Ex) or in the out-of-plane (Ey) directions. These forces are of an almost triangular distribution along the height of this bridge with the maximum value applied at the key of the central arch. Moreover, the base shear that results by applying these equivalent horizontal seismic forces is approximately equal to the base shear that results from the dynamic spectral analyses (Manos 2015c). This is done by adjusting the amplitude of the equivalent horizontal seismic forces. In what follows results from this second type of analyses are presented and discussed.

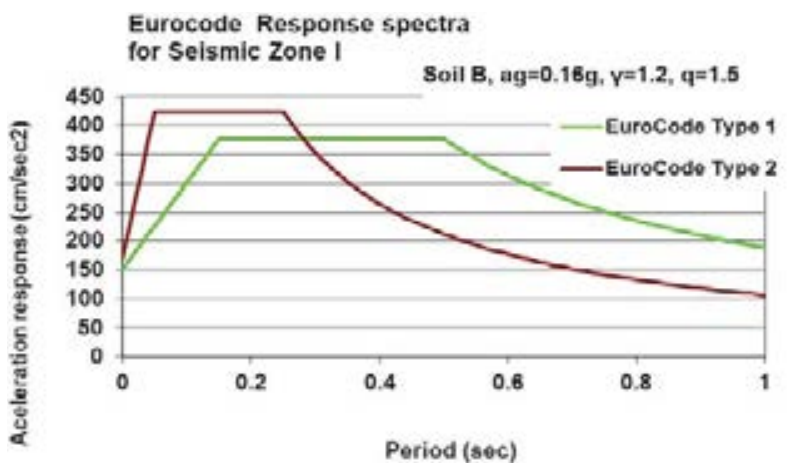

Figure 13. Design acceleration spectral curves.

Load combinations which included the simultaneous application of the deal load (D) and the equivalent horizontal seismic forces either in the in-plane $(\mathrm{D}+\mathrm{Ex})$ or in the out-of-plane (D + Ey) directions have been considered. The obtained deformation and stress results for the Saint Vissariona stone masonry bridge as obtained from these load combinations are shown in the following figures 14 to 16 . Figure 14 shows the deformation and in-plane stress distribution patterns of Saint Vissariona bridge due to its dead load. As can be seen in this figure, the deformation of the key of the central arch due to dead load is relatively small (uz=-3.46mm). In addition the maximum tensile stress value is also relatively small $(\sigma \mathrm{max}=0.200 \mathrm{MPa})$ and develops at a confined region at the deck of the bridge above the left and right abutments. The minimum compressive stress value is of the order of $\sigma \mathrm{min}=-0.70 \mathrm{MPa}$ that can be easily sustained by such stone masonry construction. Figure 15 shows the deformation and in-plane stress distribution patterns of Saint Vissariona bridge due to the load combination including the dead load and the in-plane equivalent horizontal seismic forces. Again, the in-plane deformation of the key of the central arch due to this load combination is relatively small ( $u x=1.70 \mathrm{~mm} \quad u z=-4.51 \mathrm{~mm}$ ). However, it can be seen that the region at the deck above the left abutment develops a considerable increase in the maximum tensile stress value 
$(\sigma \max =0.500 \mathrm{MPa})$. Such tensile stress values represent a relatively high tensile stress demand for stone masonry. The region that this high tensile stress value develops correlates with the deformation pattern of the bridge for this load combination. Again, the minimum compressive stress value is of the order of $\boldsymbol{\sigma}_{\min }=-0.70 \mathrm{MPa}$ that can be easily sustained by such stone masonry construction.

\section{Dead Load}

$\mathbf{u}_{\mathbf{z}}=-3.46 \mathrm{~mm}$
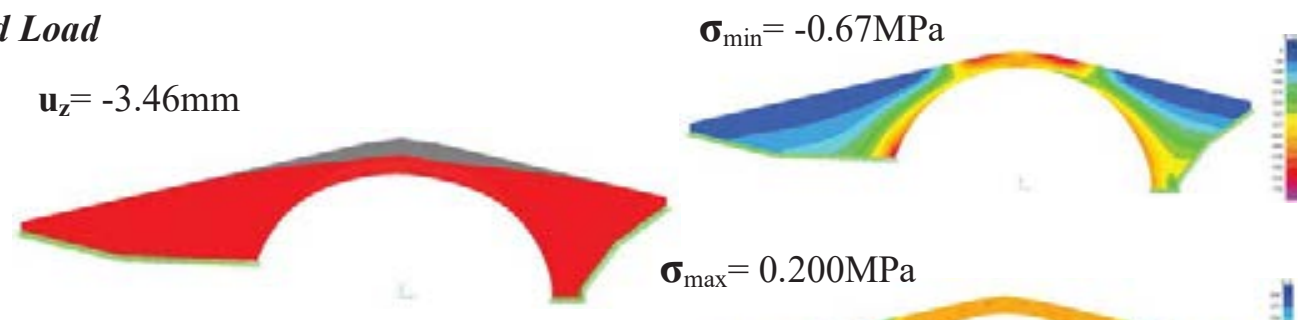

$\boldsymbol{\sigma}_{\max }=0.200 \mathrm{MPa}$

Figure 14. Deformation and in-plane stress distribution patterns of Saint Vissariona bridge due to the dead load

\section{Dead Load + Ex}

$$
\boldsymbol{\sigma}_{\min }=-1.10 \mathrm{MPa}
$$
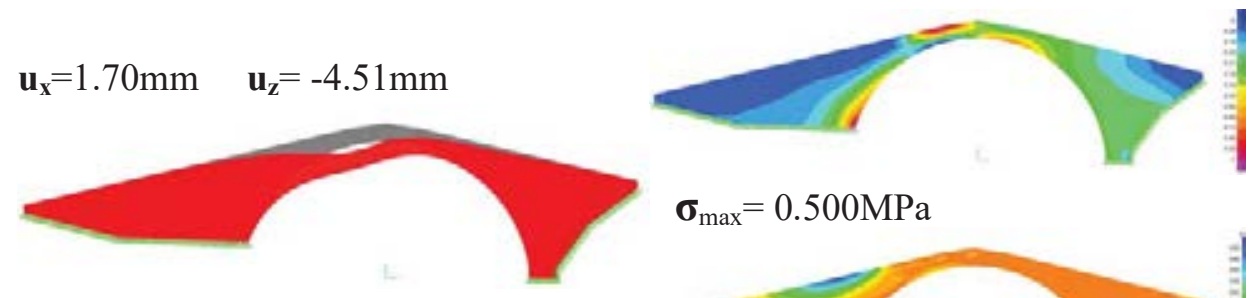

$$
\boldsymbol{\sigma}_{\max }=0.500 \mathrm{MPa}
$$

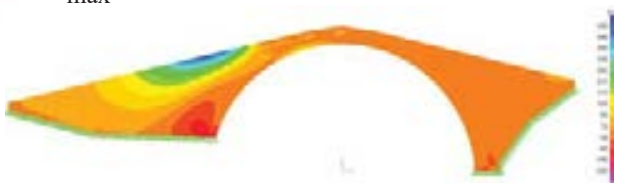

Figure 15. Deformation and in-plane stress distribution patterns of Saint Vissariona bridge due to dead load and equivalent in-plane seismic horizontal forces

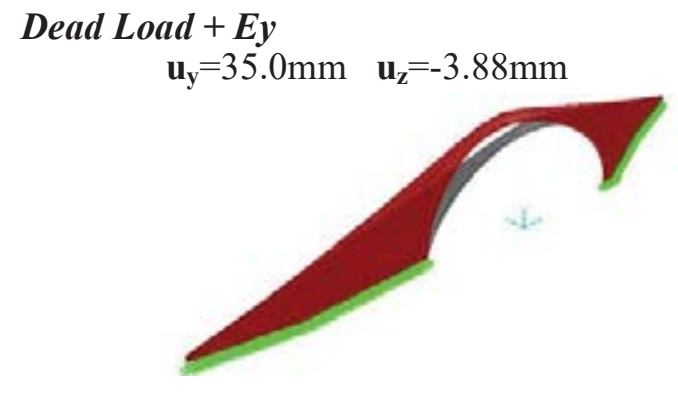

Bottom face $\boldsymbol{\sigma} \max =2.07 \mathrm{MPa}$

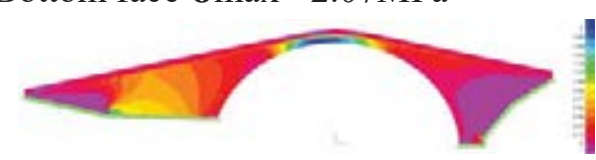

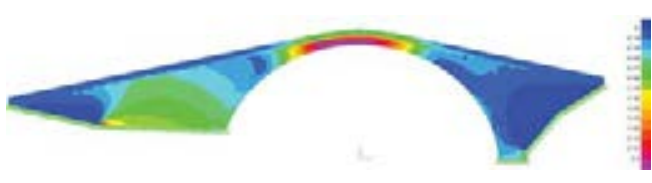

Top face $\boldsymbol{\sigma m a x}=3.0 \mathrm{MPa}$

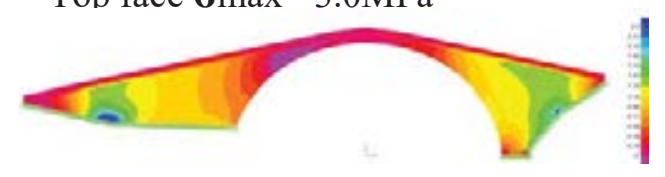

Bottom face $\boldsymbol{\sigma} \min =-5.00 \mathrm{MPa}$

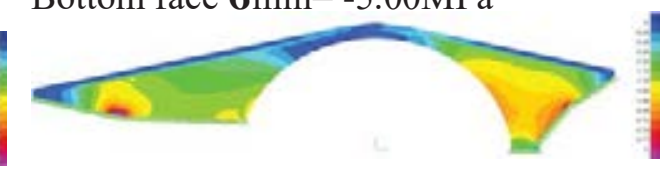

Figure 16. Deformation and out-of-plane stress distribution patterns at the facades (top and bottom) of Saint Vissariona bridge due to dead load and equivalent out-of-plane seismic horizontal forces 
Figure 16 shows the deformation and out-of-plane stress distribution patterns at the two extreme faces (top and bottom) of Saint Vissariona stone masonry bridge due to the load combination of the dead load and the out-of-plane horizontal equivalent seismic forces. As can be seen in this figure, the out-of-plane horizontal deformation of the key of the central arch due to this load combination is relatively large (uy $=35.0 \mathrm{~mm} u z=-3.88 \mathrm{~mm}$ ). As a result, large maximum tensile stress values develop at the central region of the main arch (Bottom face $\sigma \max =2.07 \mathrm{MPa}$ ) as well as at the region where the left abutment joins the foundation. Such tensile stress values represent a relatively very high tensile stress demand for stone masonry. Again, the minimum compressive stress value is of the order of $\sigma \mathrm{min}=-5.00$ that, despite the relatively large amplitude, can be easily sustained by such stone masonry construction. As can be seen from the results of such a simplified numerical analysis the Saint Vis-sariona bridge can be quite vulnerable for earthquake ground motions that are dictated from the cur-rent seismic code. According to historical information this stone masonry bridge was built on 1514 A.D. In 1967 this stone masonry bridge was declared cultural monument by the Greek Ministry of Culture and in 2000 the surrounding area was also declared as a region in need of special protection by the same Ministry (Greek Government Gazette 1967). During the last century the most intense earthquake activity related to this bridge must be considered the Sofades in Karditsa earth-quake sequence on 30th of April 1954 which is assigned by Papazachos et al. (1989) a magnitude of 7.0 at the Richter scale with an epicenter approximately $50 \mathrm{~km}$ from the site of Saint Vissariona bridge. It was not possible up to now to find any record of structural damage relating this earthquake to Saint Vissariona bridge despite the fact that are reports of substantial structure damage which was widespread in the Thessalia prefecture.

\section{INFLUENCE OF THE FOUNDATION DEFORMABILITY.}

In the preceding sections 3 and 4 the piers and the abutments of the examined stone masonry bridges were assumed to be supported in non-deformable soil-foundation interface. In what follows a preliminary study of the influence of deformable soil where a stone masonry is found is carried out. The Plaka stone masonry bridge collapsed on the 1st of February 2015 due to the flooding of the Arachtos river. Figure 17a depicts this bridge as it was standing before this collapse whereas figure $17 \mathrm{~b}$ shows the remains of the abutments after the collapse of the bridge due to the flooded river which is also shown in the same figure. Figure 17c depicts the collapsed bridge ten months afterwards (12th December 2015) whereas figure 17d depicts the picture (19th October 2019) of the reconstruction of the old bridge in the same overall geometry and using materials and constructions techniques as close as possible to the original construction. Recently (7th December 2019), it was announced that the primary arch of the reconstructed new Plaka stone masonry bridge was completed by placing the top key stones at the top- middle of this primary arch. Manos et al. (2017) investigated, through a simplified linear analysis approach, the effect of the flooding forces acting on the Plaka bridge structure adopting the assumption that the foundation of its mid-pier footing was on a relatively flexible soil.

In addition, the damage suffered by the main arch during an explosion that occurred in 1944, was also included in this study. More information can be found in Manos et al 2017. 

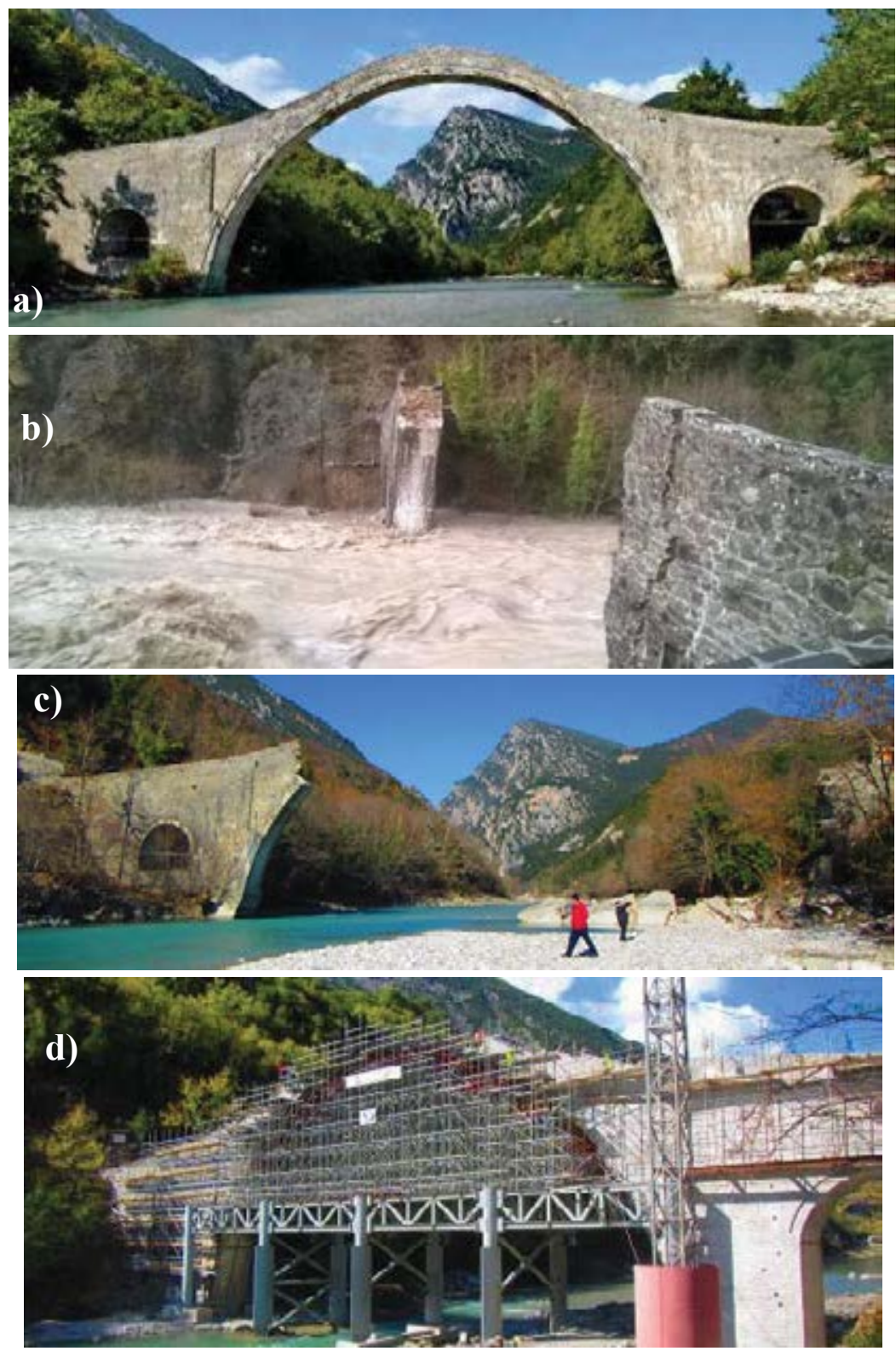

Figure 17. Collapse from flooding and reconstruction of the Plaka stone masonry bridge

Figures 18a,b,c depict the displacement and stress response of the Plaka bridge under the combined action of the gravity and flooding forces, taking into account the arch damage as well as the deformability of the soil under the footing of the mid-pier. The maximum vertical deflection response, shown in figure $18 \mathrm{a}$, is equal to $21.95 \mathrm{~mm}$ at the top middle of the central arch. At the same location, the horizontal in-plane displacement is equal to $4.5 \mathrm{~mm}$ ( $\mathrm{y}-\mathrm{y}$ direction), whereas the out-of-plane horizontal displacement ( $\mathrm{x}-\mathrm{x}$ direction, flow of river) is equal to $0.87 \mathrm{~mm}$. The maximum (tensile) stress response is depicted in figures $18 \mathrm{~b}$ and $18 \mathrm{c}$. As can be seen, at the central arch region (figure 18c) the maximum stress value is equal to $0.764 \mathrm{MPa}$ whereas at the left relief arch region the maximum stress value us equal to $2.579 \mathrm{MPa}$ (figure $18 \mathrm{~b}$ ). 
Simos et al. (2017). Investigated the collapse of the Plaka Stone Bridge due to extreme flooding using high fidelity, three-dimensional non-linear numerical analysis and sensitivity studies. The potential of a number of postulated scenarios in initiating failure and leading to the eventual collapse of the bridge were explored aided by sensitivity analyses relying on non-linear finite element modeling, augmented by actual material properties of the structural elements deduced from laboratory tests following the collapse. More information can be found in Simos at al 2017.

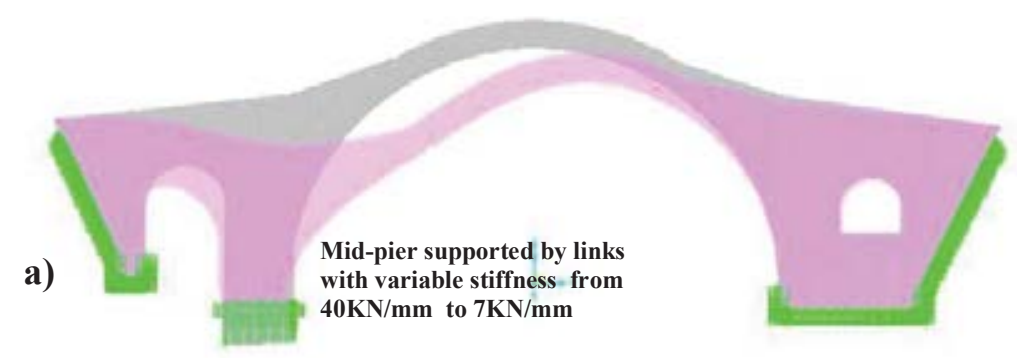

b)
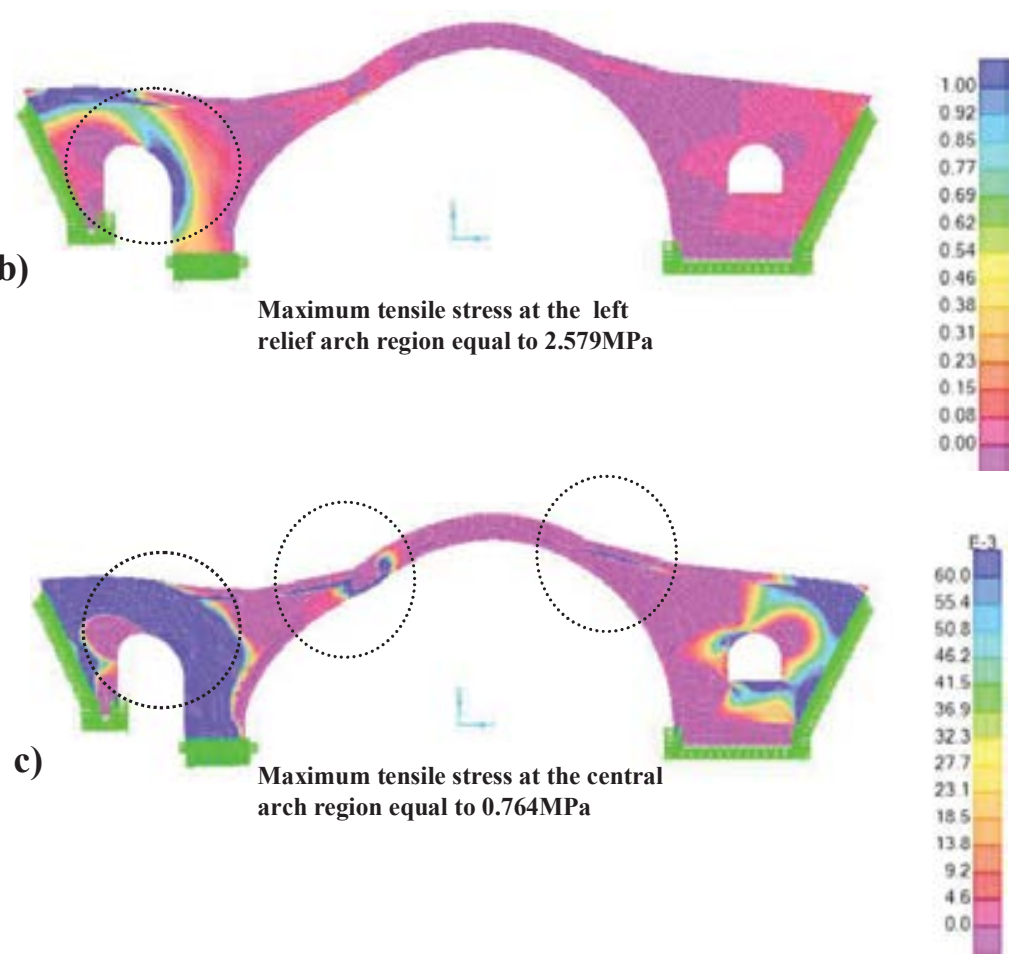

Figure 18. Displacement and stress response of the Plaka stone masonry bridge

The numerical analysis and the failure scenario postulated and presented in detail in this study tend to support that the triggering of the collapse and the most-likely cause was the undermining by the flood (scouring of the river bed and hydrodynamic loads) of the central pier. In what follows the Plaka Bridge is numerically simulated this time together with a volume of soil under its foundation of the piers and the abutments withn the river bed, as is shown in figure 19. Elastic properties are assigned to this volume in an effort to approximate the flex- 
ibility of the foundation under the footings of the piers located within the river bed and to further research on the collapse mechanisms.

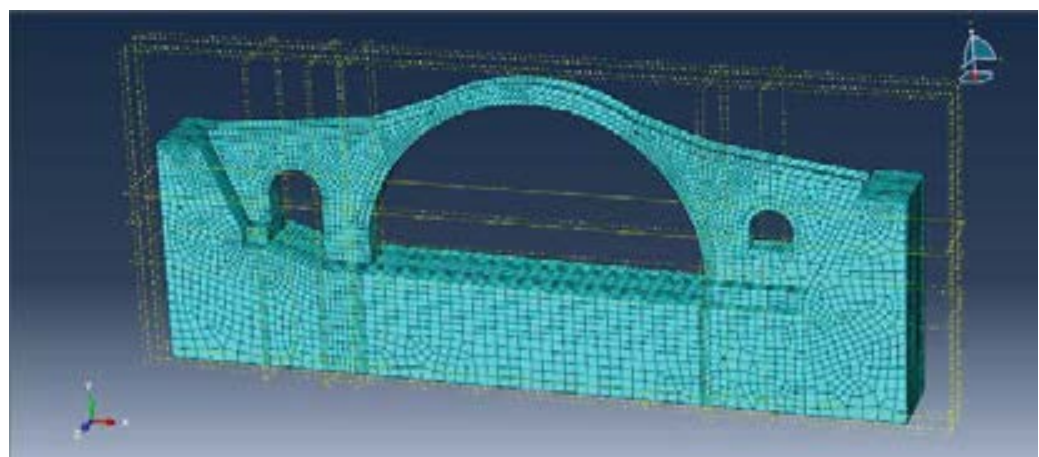

Figure 19. Numerical simulation of the Plaka bridge together with a volume of soil.

Apart from numerically simulating the flexibility of the foundation in these way seven critical cross sections, five at the central arch, one at the left relief arch and one at the right relief arch, were numerically simulated employing contact surfaces which could allow a non-linear palstification response to develop, according to an assumed cohesive constitutive law. In order to check how this numerical model reproduces the effect of the foundation flexibility, simulated as described, the gravity forces were gradually applied till they reached an final level equal to the gravity forces amplified by a factor of 2 . The obtained response, in terms of amplified displacement response is shown in figure $20 \mathrm{a}$ whereas figure $20 \mathrm{~b}$ is indicating the plastification of the mentioned contact surfaces.

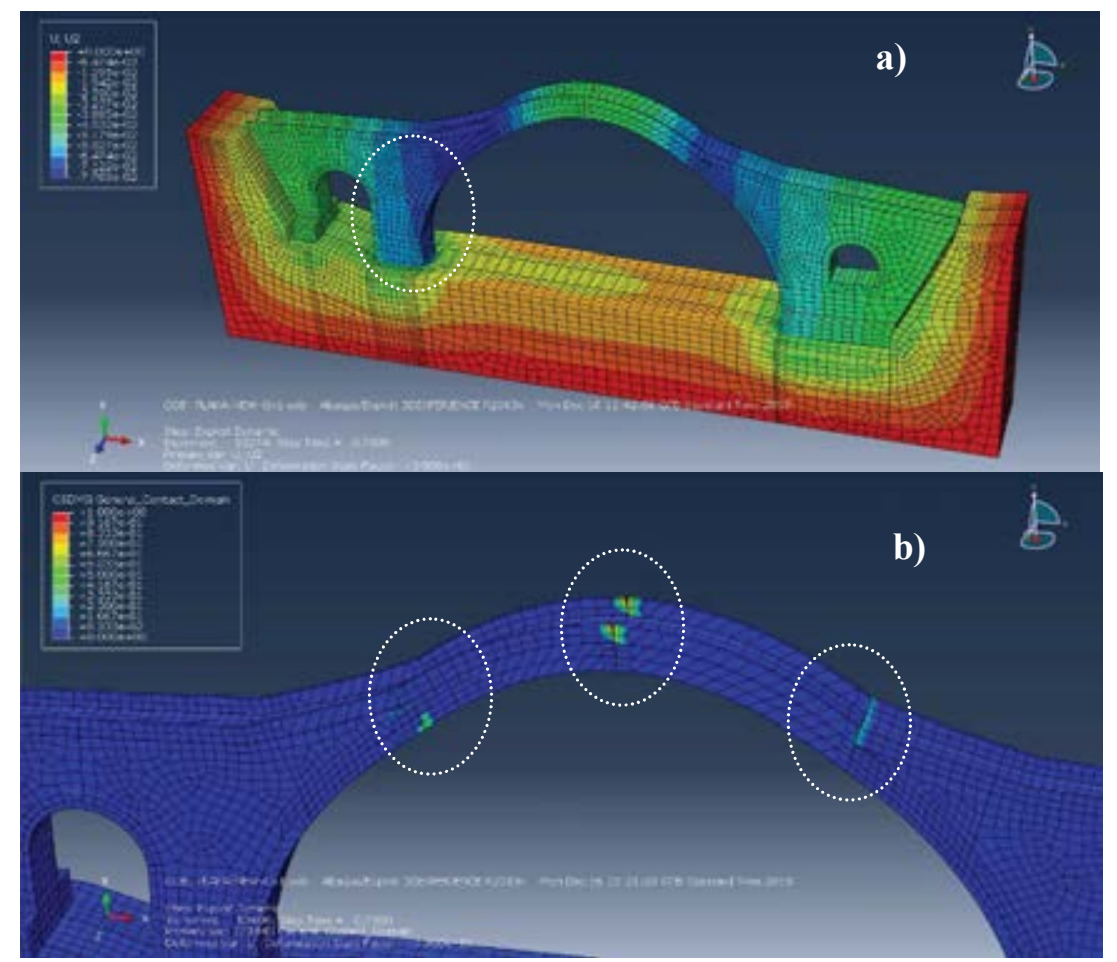

Figure 20. Vertical deflection of the mid-pier footing (a) together with the corresponding plastification (b) of critical cross-sections of the Plaka bridge for vertical forces $80 \%$ of gravity. 
Figures 20a and 20b depict the numerical response when the applied forces reach the level of $80 \%$ of gravity. At this stage the vertical deflection of the footing of the mid-pier, due to the flexibility of the underlying soil, is approximately $30 \mathrm{~mm}$. This deflection of the footing is sufficient to cause the initiation of plastification in three contact surfaces at the encircled critical regions of the central arch, indicated in figure 20b. It is of interest to observe that two of the locations of the plastification of figure $20 \mathrm{~b}$ coincide with the regions of tensile stress concentration in figure $18 \mathrm{c}$.

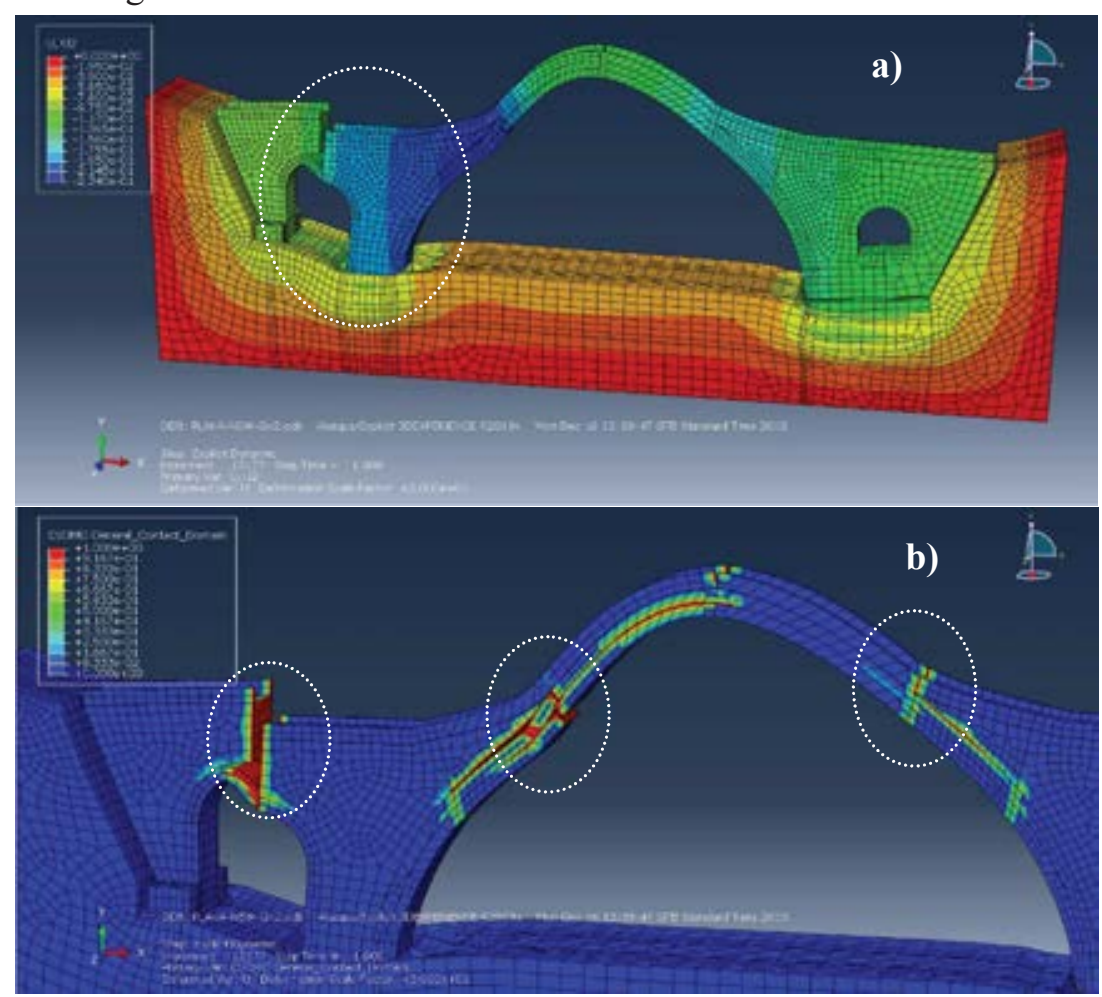

Figure 21. Vertical deflection of the mid-pier footing (a) together with the corresponding plastification (b) of critical cross-sections of the Plaka bridge for vertical forces $200 \%$ of gravity.

Figures $21 \mathrm{a}$ and $21 \mathrm{~b}$ depict the numerical response when the applied forces reach gragually the level of $200 \%$ of gravity. At this stage the vertical deflections of the footing of the midpier, due to the flexibility of the underlying soil, reach the level of $200 \mathrm{~mm}$. Such level of deflections of the footing are detrimental to the structure as can be seen figure $21 \mathrm{~b}$. The plastification is widespread in all the contact surfaces being more pronounced at the left and right critical regions of the mid-pier. These plotted deformation pattern of the bridge bears resemblance to the collapse mechanism of the Plaka bridge depicted in figures $17 \mathrm{~b}, 17 \mathrm{c}$. Thus, the numerical response obtained at the end of the described gradual loading sequence shows signs of non-linear structural response which can be considered as realistic. This investigation is still under way. Stone bridge behaviour employing advanced non-linear analyses tools were also utilized by Drosopoulos et al (2006), Korompilias (2015), Simos et al. (2018).

\section{CONCLUSIONS}

- Stone masonry construction has a long tradition in many places worldwide. Stone masonry bridges built many centuries ago are one such example. Despite the rigidity and resilience of stone masonry bridges they are in need of maintenance in order to preserve them as part of 
the built cultural heritage. Towards this end in-situ measurement campaigns were conducted on a number of stone masonry bridges in order to identify their dynamic characteristics in terms of eigen-frequencies, eigen-modes and damping properties. This information is believed to rep-resent a valuable basis for building realistic numerical simulations of the structural behaviour of such bridges as well as for their structural health monitoring.

- The simplified numerical analyses yielded numerical predictions of bridge deformations and stresses that are useful in understanding the structural behaviour and the structural damage potential for such masonry structures.

- The peak tensile values predicted when design seismic forces were applied for the Saint Vissariona bridge are many times above the tensile strength of the stone masonry thus indicating the severe potential structural damage for this old stone masonry bridge from the design earthquake. The most vulnerable parts of the bridge, as obtained from the location of the peak tensile stress concentration, is a wide area at the crest of the main central arch of the bridge as well as at the abutment near the foundation.

- The integrity of the stone masonry in various parts of the bridge is an additional maintenance issue of considerable importance. Intervention recommendations for such stone masonry bridges should include clauses for applying preparatory actions of measurements and analyses like the ones included here together with established principles that govern a major retrofitting / maintenance effort for cultural heritage together with effective retrofitting / maintenance techniques that are proven to be durable.

- The described system identification technique can also be utilized in identifying changes of stiffness that may be linked to specific actions, such as earthquake activity, and thus serve as warning for certain maintenance counter-measures.

- As shown from the numerical predictions, the flexibility of the foundation, which may be partly attributed to long or short term erosion of the bridge footings, results in detrimental response for the Plaka bridge. These predicted peak tensile stress values are well beyond the stone masonry strength. Consequently, they could well have contributed towards the February 2015 collapse.

- The peak tensile values predicted when design seismic forces were applied for the Plaka bridge are many times above the tensile strength of the stone masonry thus indicating the severe potential structural damage for this old stone masonry bridge from the design earthquake. The most vulnerable parts of the bridge, as obtained from the location of the peak tensile stress concentration, is a wide area at the crest of the main central arch of the bridge as well as the mid-pier internal side footing. Thus, these earthquake vulnerability predictions for the Plaka bridge indicate that had the bridge not collapsed from flooding the design earthquake would have led to its structural damage and its partial collapse.

- Results form advanced non-linear numerical analyses show that such numerical simulations can reproduce in a realistic way the collapse failure scenario and support the hypothesis that the most-likely cause of the collapse of the Plaka bridge.

\section{REFERENCES}

[1] Aoki T., et al, (2007), "Theoretical and Experimental Dynamic Analysis of Rakanji Stone Arch Bridge, Honyabakei, Oita, Japan," 7th International Conference on Motion and Vibration Control, MOvIC 04. 
[2] Drosopoulos G.A., Stavroulakis G.E., Massalas C.V., (2006) "Limit analysis of a single span masonry bridge with unilateral frictional contact interfaces," Engineering Structures 28 (2006) 1864-1873.

[3] EAK (2000), Provisions of Greek Seismic Code 2000 , OASP, Athens, December 1999. Revisions of seismic zonation introduced in 2003.

[4] Eurocode 8 (2004) - Design of structures for earthquake resistance - Part 1 and Part 2: Bridges, DRAFT No 3. European Committee for Standardization; 2004.

[5] Galeridis A. (1995) "The Stone Masonry Bridges in Thessalia", Technical Chamber of Greece, Eptalofos, Athens, Greece (In Greek).

[6] Gazette of the Greek Government (1967), (ФEK 352/B/31-5-1967) and (ФEK 194/B/21-2-2000), (in Greek).Grassos G. (2007), "The stone masonry arch bridges of Greece", Center of environmental education Makrinitsas, Editor G. Grassos, ISBN: 978-960-98043-9-4, (in Greek). http://kpe-makrin.mag.sch.gr.

[7] ITSAK (2019) Institute of Engineering Seismology and Earthquake Engineering (ITSAK), Data Base of Greek Earthquake Strong Motions.

[8] Kiyono J., et al. (2012), "Seismic Assessment of Stone Arched Bridges," 15 WCEE, Lisboa, Portugal, 2012.

[9] Korompilias D., (2015), "Study of the inelastic behaviour of the Konitsa bridge using an inelastic model for masonry and applying strengthening methods," $\mathrm{PhD}$ Thesis, Univ. Of Patras, Greece, (in Greek).

[10] Manos G.C. (2011), "Consequences on the urban environment in Greece related to the recent intense earthquake activity", Int. Journal of Civil Eng. and Architecture, Dec., Volume 5, No. 12 (Serial No. 49), pp. 1065-1090.

[11] Manos G.C. et al. (2015a), "Field experiments for monitoring the dynamic soilstructure-foundation response of model structures at a Test Site" Journal of Structural Engineering, American Society of Civil Engineers, Special Issue "Field Testing of Bridges and Buildings, D4014012, Vol. 141, Issue 1, January 2015.

[12] Manos G.C. and Kozikopoulos E., (2015b) "In-situ Measured Dynamic Response of the Bell Tower of Agios Gerasimos in Lixouri-Kefalonia, Greece and its Utilization of the Numeri-cal Predections of its Earthquake Response", COMPDYN 2015, Greece.

[13] Manos G.C., Kotoulas L., Soulis V., Felekidou O. (2015c), "Numerical Simulation of the Limit Non-Linear Behaviour of Unreinforced Masonry under In-plane State of Stress from Gravitational and Seismic Actions", COMPDYN 2015, Greece.

[14] Manos G.C., Nick Simos N. and Kozikopoulos E. (2016) "The Structural Performance of Stone-Masonry Bridges", Chapter 4, Structural Bridge Engineering, ISBN 978-95351-2689-8, Print ISBN 978-953-51-2688-1, http://dx.doi.org/10.5772/64752.

[15] Manos G.C., Kozikopoulos E.,Kotoulas L., Simos N. (2017), "In-situ Measurements Related to the Performance of Stone Masonry Bridges in Greece", COMPDYN 2017, 6th ECCOMAS Thematic Conference on Computational Methods in Structural Dynamics and Earthquake Engineering, M. Papadrakakis, M. Fragiadakis (eds.), Rhodes Island, Greece.

[16] Manos G., Simos N., Lambri-Gaitana N. (2019), "Dynamic and Seismic Behaviour of Stone Masonry Brisges in Greece Utilizing In-situ Measurements and Numerical Pre- 
dictions", COMPDYN 2019, 7th ECCOMAS Thematic Conference on Computational Methods in Structural Dynamics and Earthquake Engineering, M. Papadrakakis, M. Fragiadakis (eds.), Crete, Greece.

[17] Milas Iraklis, (2016), "Stone Bridges", Ethnos Travel Book, Ethnos Publications, ISBN:978-960-577-122-5 (in Greek).

[18] Ozden Caglayan B., Kadir Ozakgul and Ovunc Tezer, (2012), "Assessment of a concrete arch bridge using static and dynamic load tests" Structural Engineering and Mechanics, Vol. 41, No. 1 (2012) 83-94

[19] Papazachos B.K. and Papazachou K. (1989) "Earthquakes in Greece", Ziti publishers, Thessaloniki, Greece, (In Greek).

[20] Psimarni K., Georgopoulos A., Balodimos D.D. (2000), "Development of a Geographic In-formation System for the Traditional Bridges of Central Zagori,", Report to the Municipal-ity of Zagori, in Greek.

[21] Ruocci G., Quattrone A., Zanotti Fragonara L., Ceravolo R., De Stefano A., (2013) "Experimental Testing of a Masonry Arch Bridge Model Subject to Increasing Level of Damage", IRIS, Chapter 6, Industrial Safety and Life Cycle Engineering, VCE Vienna Consulting Engineers, www.vce.at, ISBN 978-3-200-03179-1.

[22] SAP2000, Integrated Software for Structural Analysis and Design, Computers and Structures Inc.

[23] Sevim Barrs, et al., (2011), "Finite element model calibration effects on the earthquake re-sponse of masonry arch bridges," Finite Elements in Analysis and Design, 47 (2011), $621-634$

[24] Simos N. and. Manos G.C, (2013), "Numerical Analysis of Seismic Response of Natural Stone Arch Bridges-Field Observations and a Case Study," COMPDYN 2013, http://www.eccomasproceedings.org/cs2013/

[25] Simos N., Manos G.C., Kozikopoulos E., Kotoulas L. "On the Assessment of the Plaka Bridge Collapse using Non-linear Analysis Preventable or Doomed?", COMPDYN 2017, 6th ECCOMAS Thematic Conference on Computational Methods in Structural Dynamics and Earthquake Engineering, M. Papadrakakis, M. Fragiadakis (eds.), Rhodes Island, Greece, 15-17 June 2017.

[26] Simos N., Manos G.C., Kozikopoulos E. (2018), "Near- and far-field earthquake damage study of the Konitsa stone arch bridge", Engineering Structures 177 (2018) 256-267, https://doi.org/10.1016/j.engstruct.2018.09.072. 